\title{
Bidirectional Quasi Z Source Inverter with Fuzzy Logic Controller for Traction Motor Speed Control
}

\author{
Chandra Prabha.$G^{1}$, Jamuna.P $P^{2}$ \\ $P G$ Scholar ${ }^{1}$, Associate Professor ${ }^{2}$ \\ (Department of EEE, Nandha Engineering College, India)
}

\begin{abstract}
The Fuzzy Logic Controller is implemented to control the speed of the electric vehicle applications. The speed and output voltage of the motor, controlled by Proportional Integral (PI) controller and Fuzzy Logic Controller can be compared. During starting and braking of the electric vehicle applications the performance comparison is done. The reverse power flow is obtained by Bidirectional Quasi-Z-source inverter (BQ-ZSI). The inverter with the design and operation is analyzed. The Electric vehicles and hybrid electric vehicles are emerging vehicles in the future generation. The power flow and speed can be controlled during starting and braking of the vehicles. The comparison of the speed control using PI and Fuzzy controller is done and output results. The simulation results are presented to prove the functionality of the circuit and the effectiveness of the proposed control strategy.
\end{abstract}

Index Terms: Bidirectional quasi-Z-source inverter (BQ-ZSI), electric vehicle (EV) applications, feed-forward compensation, reverse power flow, small signal model.

\section{Introduction}

The evolution of Electric Vehicles (EV) creates a global push and provides better replacement of the fuel based vehicles. The Vehicles are charged by batteries and the power flow during starting and braking operations can be designed by Bidirectional quasi Z Source Inverter. The power (SDP) by $15 \%$ over the dc-dc converter with the VSI topology, which reduces the total cost and further improves the efficiency of the traction drive system. However, the input current of ZSI is not continuous, which will shorten the lifetime of the battery pack and degrade the vehicle performance. By rearranging the components in the Z-source network, a new topology called quasi-Z-source inverter (QZSI) is proposed. The QZSI realizes the continuous input current, at the same time retaining all the merits of the ZSI, which makes it a good candidate for EV applications. However, the traditional QZSI only allows unidirectional power flow from the dc to the ac side. The traction drive system requires the reverse power flow to realize the regeneration break of the EV. To achieve the bidirectional power flow capability, the same approach as in is utilized and the diode in the quasi-Z-source network (QZSN) is replaced by an active switch. A similar approach is also utilized in the bidirectional ZSI .However, much of the previous operation mode analysis was based on the topology of the ZSI and mainly focused on the power flow from the dc to the ac side. To better understand the circuit, this paper first gives a detailed circuit analysis of the bidirectional quasi-Z-source inverter (BQ-ZSI) during the regeneration mode, i.e., when the power flows from the ac to the dc side. The analysis proves that with the active switch, the inductor currents in the QZSN can be reversed and the energy from the ac side can be delivered to the dc source. The analysis also shows that, unlike in the ZSI, part of the dc link ripple current will be absorbed by the two capacitors in the QZSN and not go through the dc source, which provides a better operating condition for the battery pack in EV. Furthermore, with the additional switch, the discontinuous conduction mode (DCM) can be avoided and the BQ-ZSI can have a better performance with small inductance or under low power factor condition, such as when the electric motor is operated with a light load. Based on the circuit analysis, the small signal model can be obtained, and the control algorithm of the BQ-ZSI in EV applications can be developed. By rearranging the components in the Z-source network, a new topology called quasi-Z-source inverter (QZSI) is proposed. The QZSI realizes the continuous input current, at the same time retaining all the merits of the ZSI, which makes it a good candidate for EV applications. 


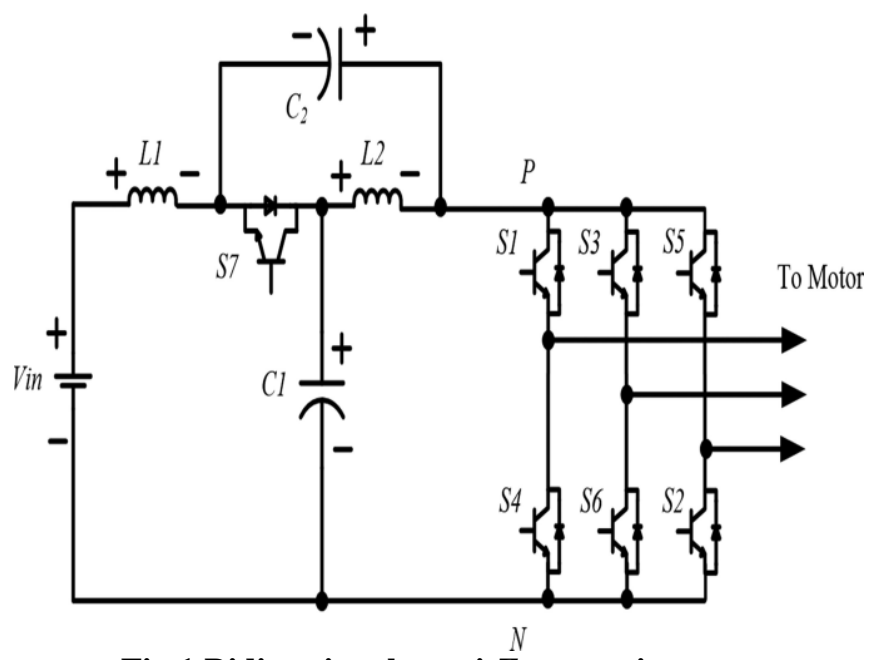

Fig.1 Bidirectional quasi-Z-source inverter

\section{A. Control of $s 7$}

During the regeneration mode, the switching pattern of $S 7$ is complementary with the shoot-through pattern of the three phase bridge. When the three-phase bridge is in the shoot through state, $S 7$ is open. The body diode is reversely blocked and the voltage boost function can be realized. When the three phase bridge is in the non-shoot-through state, $S 7$ is closed. The reverse current goes through $S 7$ and feeds the energy back to the dc source. For safety purposes, a suitable dead time needs to be inserted between the control signals of the shootthrough state and $S 7$. Otherwise, the two capacitors in the QZSN may be short-connected through S7, which will cause damage of the devices.

\section{B. Current Modes Analysis}

Without losing generality, assume $L 1=L 2$ in $L 1$ and $L 2$ are always the same. However, the voltages on $C 1$ and $C 2$ are not the same. When driving an electric motor, the instantaneous current flowing through the dc link during the non-shoot-through state can be expressed as

$$
i P N=S 1 \cdot i a+S 3 \cdot i b+S 5 \cdot i c=I P N+{ }^{\wedge} i P N
$$

where $i a, i b$, and $i c$ are the instantaneous ac side three-phase current. $I P N$ is the dc component and ${ }^{\wedge} i P N$ is the ac component of $i P N$. $S 1, S 3$, and $S 5$ are the switching functions. When $S x=1$, switch $S x$ is closed, and when $S x=$ 0 , switch $S x$ is open ( $x=1,3$, or 5). From (1), it can be noted that the value of $i P N$ changes with time. Utilizing the principle of superposition, $i P N$ can be written as the sum of $I P N$, which is related to the active power of the ac side, and ${ }^{\wedge} i P N$, which is related to the switching action of the three-phase inverter and the reactive power of the ac side. The average value of ${ }^{\wedge} i P N$ over one fundamental period is zero. According to the topology shown in Fig. 1, during the nonshoot-through state, $S 7$ is closed. ${ }^{\wedge} P N$ can circulate through two capacitors $C 1$ and $C 2$, switch $S 7$, and dc link PN. Depending on the impedance of the dc source, part in $L 1$ and $L 2$ are always the same. However, the voltages on $C 1$ and $C 2$ are not the same. The average value of $i P N$ over one fundamental period is zero. According to the topology shown in Fig. 1, during the non shoot- through state, $S 7$ is closed. $i P N$ can circulate through two capacitors $C 1$ and $C 2$, switch $S 7$, and dc link PN. Depending on the impedance of the dc source, part of ${ }^{\wedge} i P N$ will be absorbed by the capacitors and not flow through the inductors and the dc source, which improves the operating condition of the battery pack in EV. This is different from the ZSI and traditional QZSI, but similar to the traditional VSI where a dc-link capacitor will absorb the current ripple from the ac side. $I P N$ will go through the QZSN. This part of the current is directly related to the energy transfer between the dc side and the ac side.

\section{C.AC Side Controller Design}

The ac side controller is utilized to control the ac motor. Since the dc-link voltage is stabilized by the dc side controller, existing motor control algorithms, such as FOC orV/Hz control, can be directly implemented and is not described in detail in this paper. However, to achieve a good system level control, the dynamics of the ac side should be designed to be much faster than the dc side to avoid oscillation. Since the shoot-through state is always restricted within the zero state of the control parameter at the dc side will impose. On the ac side. With a higher input voltage, to achieve the same dc-link voltage, the required shoot-through duty ratio will be smaller. Therefore, there will be less possibility that the dc side shoot-through duty ratio controller conflicts with the ac side controller. So the controller usually will perform better with higher end of input voltage range. The 
complete system level control algorithm is shown in Fig. 4 Without losing generality, a current regulator under a synchronous frame is implemented in the ac side controller. The ac (Alternating Current) side controller is utilized to control the ac motor. Since the dc-link voltage is stabilized by the dc side controller. To achieve a good system level control, the dynamics of the ac side should be designed to be much faster than the dc side to avoid oscillation. With a higher input voltage, to achieve the same dc-link voltage, the required shoot-through duty ratio will be smaller. So the controller usually will perform better with higher end of input voltage range.

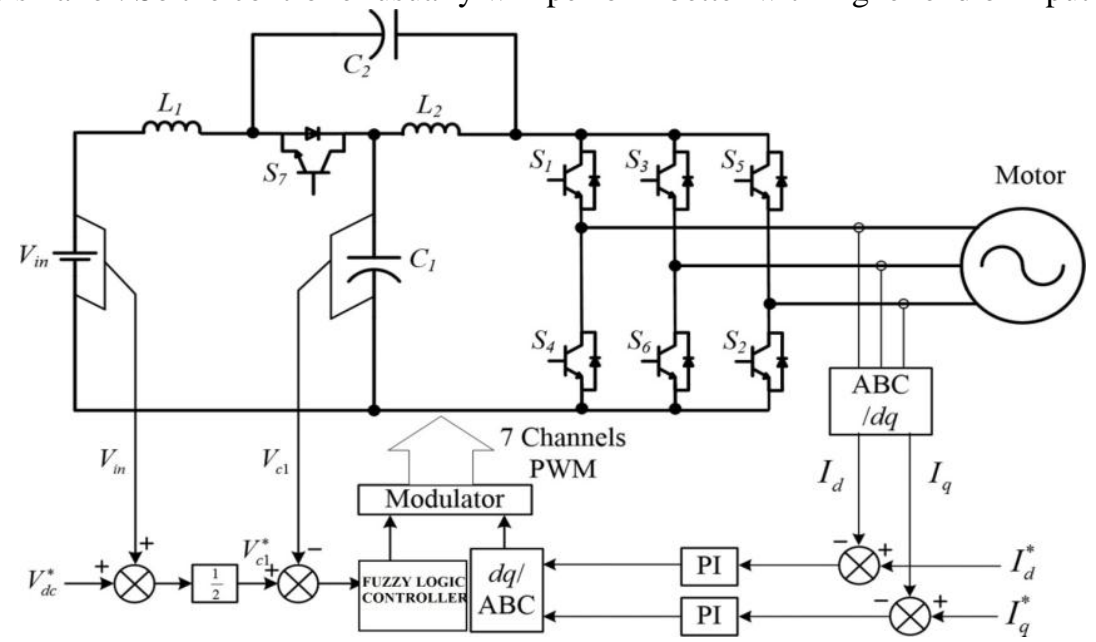

Fig.2 System model and control strategy.

\section{Pulse width modulation technique}

The modulation technique adopted for the quasi Z-source inverter is different from the conventional VSI because of the additional zero state called the shoot through state. Modifications are to be made in the traditional PWM technique so as to include the shoot through states. This can be achieved with the help of an additional constant line called the shoot through line whose magnitude is responsible for the three modulation strategies namely simple boost, maximum boost and constant maximum boost. Maximum Constant Boost Control method is used in this project.

\section{E. Implementation of fuzzy logic controller in bidirectional quasi $z$ source inverter}

The Fuzzy Logic controller takes two inputs, processes the information and outputs .The input to Fuzzy Controller are Error in voltage and Change of Error in voltage and the output is current .The Capacitor voltage is compared with the reference voltage and Error and Change in error are given as input to the Fuzzy Logic Controller. Before the details of the fuzzy controller are dealt with, the range of possible values for the input and output variables are determined. These (in language of Fuzzy Set theory) are the membership functions are used to map the real world measurement values to the fuzzy values, so that the operations can be applied on them. Values of the input variables (Error voltage) and (Change in Error voltage) are normalized range - (1 to 100) .The decision which the fuzzy controller makes is derived from the rules which are stored in the database. These are stored in a set of rules. The rules are if-then statements that are Intuitive and easy to understand, since they are nothing but common English statements. Rules used in this project are derived from common sense, data taken from typical home use, and Experimentation in a controlled environment.

\section{Steps Involved In Calculating The Crisp Output}

There are five steps in implementing the Fuzzy Logic. They are,

- Defining inputs and outputs.

- Fuzzification of input.

- Fuzzification of output.

- Create Fuzzy rule base.

- Defuzzification of output.

\section{Simulation And Experimental Results}

Simulations in MATLAB/Simulink were next performed for the four voltage-type Z-source inverters compared in this section. Most of experiments and simulation studies applied to the power systems show that the conventional controllers have large overshoots and long settling times. Also, optimizing time for control parameters, especially PI controllers, is very long and the parameters are not calculating exactly. In addition, it has been known that conventional controllers generally do not work well for non-linear, higher order and time- 
delayed linear, and particularly complex and vague systems that have no precise mathematical models. It is appropriate for rapid applications. Therefore, fuzzy logic has been applied to the industrial systems as a controller. Human experts prepare linguistic description as fuzzy rules.Determining the controller parameters with these rules, a PI controller generates the control signal by which, the fuzzy gain scheduling proportional and integral controller (FGPI) is formed.

\section{A. Output Voltage of Quasi Z Source Inverter using PI Controller}

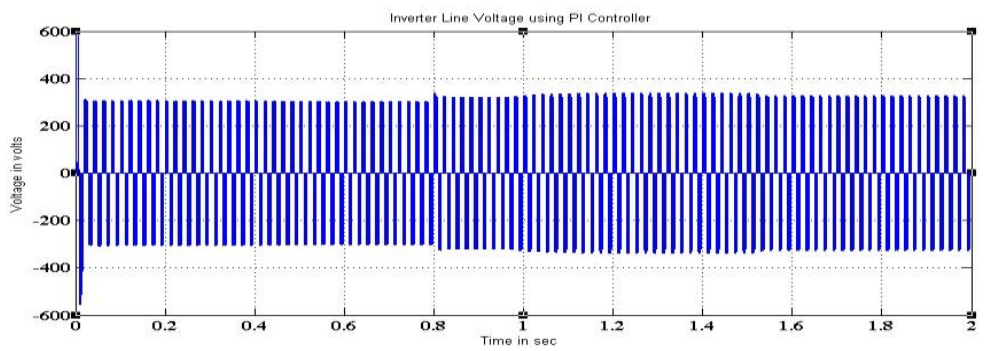

Fig 3. Output Voltage using PI Controller

B. Output Voltage of Quasi Z Source Inverter using Fuzzy Controller

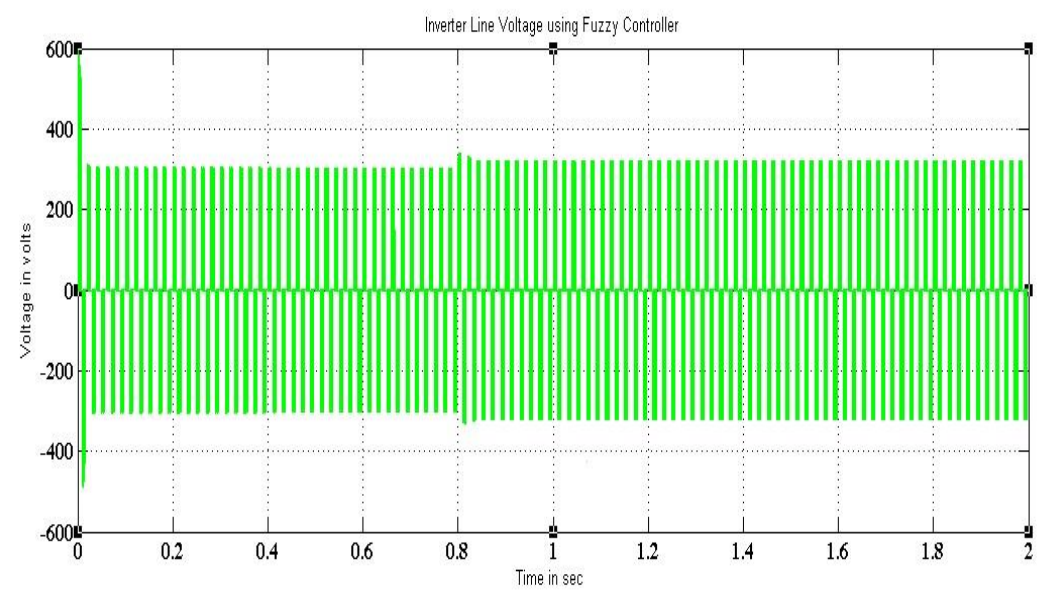

Fig 4.Output Voltage using Fuzzy Controller

C. Comparison of Capacitor Voltage (PI Vs Fuzzy Controller)

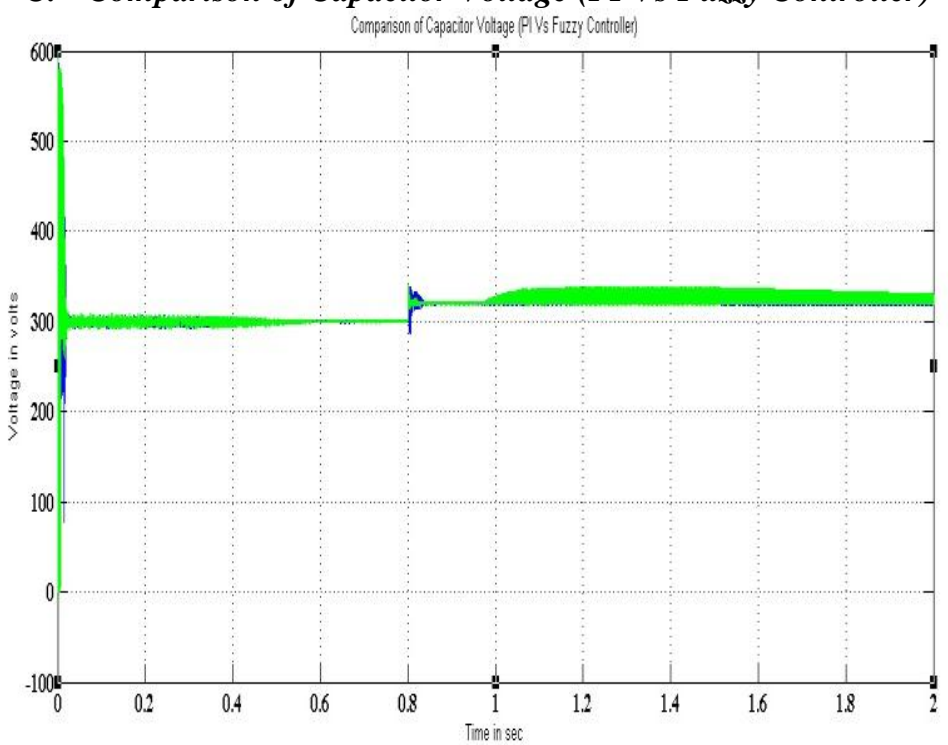

Fig. 5 Capacitor Voltage using Fuzzy controller 


\section{Comparison of speed (PI Vs Fuzzy Controller)}

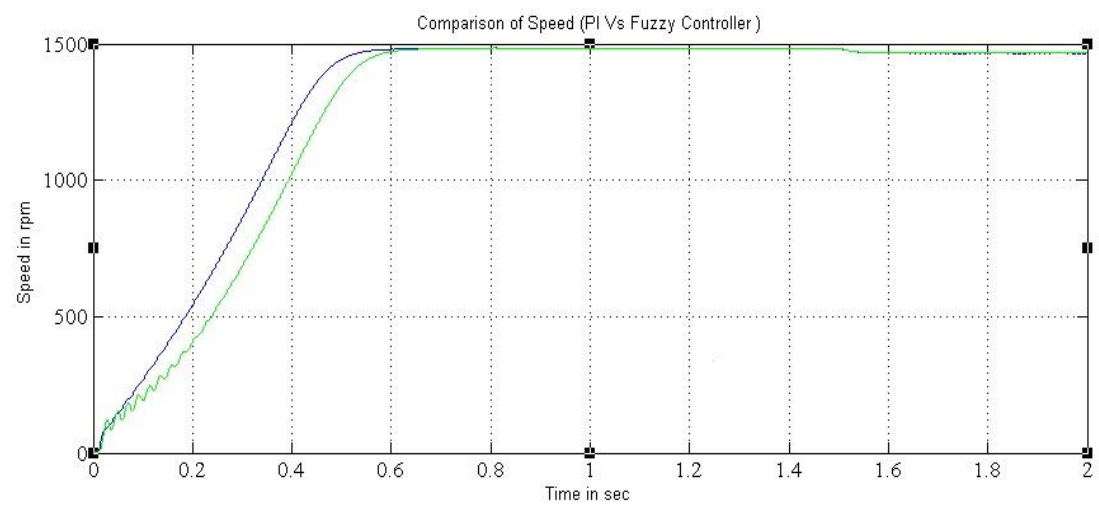

Fig. 6 Comparison of Speed

\section{References}

[1] Baoming Ge, Haitham Abu-Rub, Fang Zheng Peng, Qin Lei, Aníbal T. de Almeida, Fernando J. T. E. Ferreira, Dongsen Sun, and Yushan Liu, "An Energy-Stored Quasi-Z-Source Inverter for Application to Photovoltaic Power System," IEEE Trans. Ind. Electron., vol. 60, no. 10, pp. 4468-4481,Oct. 2013

[2] Ding Li, Poh Chiang Loh, Miao Zhu, Feng Gao, Member, and Frede Blaabjerg, "Enhanced-Boost Z-Source Inverters With Alternate-Cascaded Switched- and Tapped-Inductor Cells,” IEEE Trans. Ind. Electron., vol. 60, no. 9, pp. 3567-3578, Sep. 2013

[3] Feng Guo, , Lixing Fu, Chien-Hui Lin,Cong Li, Woongchul Choi, and Jin Wang, “ Development of an 85-kW Bidirectional QuasiZ-Source Inverter With DC-Link Feed-Forward Compensation for Electric Vehicle Applications ," IEEE Trans.Power Electron.,, vol. 28, no. 12,pp. 5477-5488, Dec. 2013

[4] Francis Boafo Effah, Patrick Wheeler, Jon Clare, and Alan Watson, "Space-Vector-Modulated Three-Level Inverters With a Single Z-Source Network,” IEEE Trans.Power Electron., vol. 28, no. 6,pp. 2806-2815, Jun. 2013

[5] H. Abu-Rub, A. Iqbal, S. Moin Ahmed, F. Z. Peng, Y. Li, and G. Baoming, "Quasi-Z-source inverter-based photovoltaic generation system with maximum power tracking control using ANFIS,” IEEE Trans.Sustainable Energy, vol. 4, no. 1, pp. 11-20, Jan. 2013.

[6] Indrek Roasto, Dmitri Vinnikov, Janis Zakis, and Oleksandr Husev, "New Shoot-Through Control ethods for qZSI-Based DC/DC Converters," IEEE Trans. Ind. Inform., vol. 9, no. 2, pp. 640-647,May. 2013

[7] Jianfeng Liu, Shuai Jiang, Dong Cao and Fang Zheng Peng, "A Digital Current Control of Quasi-Z-Source Inverter with Battery," IEEE Trans. Ind. Inform., vol. 9, no. 2, pp. 928-937, May. 2013

[8] O. Ellabban, J. Van Mierlo, and P. Lataire, "A DSP-Based dual-loop peak DC-link voltage control strategy of the Z-source inverter," IEEE Trans.Power Electron., vol. 27, no. 9, pp. 4088-4097, Sep. 2012.

[9] Seyed Mohammad Dehghan, Mustafa Mohamadian and Ali Yazdian, "Hybrid Electric Vehicle Based on Bidirectional Z-Source Nine-Switch Inverter" IEEE Trans.Vehicular Tech, vol. 59, no. 6, pp. 2641-2653,Jul. 2010

[10] Yuan Li, Shuai Jiang, Jorge G. Cintron-Rivera and Fang Zheng Peng, "Modeling and Control of Quasi-Z-Source Inverter for Distributed Generation Applications ," IEEE Trans. Ind. Electron., vol. 60, no. 4,pp. 1532-1541 Apr. 2013

\section{BIOGRAPHY}

\begin{tabular}{|c|c|}
\hline & $\begin{array}{l}\text { G.ChandraPrabha was born in Coimbatore, Tamilnadu on } 9^{\text {th }} \text { October } 1984 \text { and received } \\
\text { her BE Degree in Electronics \& Communication Engineering from Kongu Engineering } \\
\text { College, Perundurai in May 2006. Currently she is pursuing her ME Degree in Power } \\
\text { Electronics \& Drives from Nandha Engineering College, Erode. Her research interest } \\
\text { includes power electronics. }\end{array}$ \\
\hline & $\begin{array}{l}\text { P.Jamuna was born in Erode on } 3^{\text {rd }} \text { November 1983.She completed her BE Degree in } \\
\text { Electrical and Electronics Engineering in Amrita Institute of Science and Technology, } \\
\text { Coimbatore in May } 2004 \text { and ME Degree in KSR College of Engineering, Thiruchengode in } \\
\text { May 2007. She is a research scholar and currently working as Associate Professor in the } \\
\text { Department of EEE in Nandha Engineering College. }\end{array}$ \\
\hline
\end{tabular}

